Revista Brasileira de Agricultura Irrigada v.7, nº 6, p 371 - 380, 2013

ISSN 1982-7679 (On-line)

Fortaleza, CE, INOVAGRI - http://www.inovagri.org.br

DOI: $10.7127 /$ rbai.v7n600173

Protocolo 173.13 - 25/07/2013 Aprovado em 28/11/2013

\title{
DÉFICIT HÍDRICO E FATORES CLIMÁTICOS NA UNIFORMIDADE DA FLORADA DO CAFEEIRO CONILON IRRIGADO
}

\author{
Mariclei Maurílio Simões Marsetti ${ }^{1}$, Robson Bonomo ${ }^{2}$, Fábio Luiz Partelli ${ }^{3}$, Giselle \\ Sabadim Saraiva ${ }^{4}$
}

\begin{abstract}
RESUMO
A cafeicultura irrigada é uma atividade de elevada importância para o norte do Espírito Santo. O emprego da irrigação no cultivo do café Conilon capixaba tem proporcionado maior produtividade, boa uniformização da florada, e uma melhor qualidade do produto final. $O$ presente trabalho foi desenvolvido numa área localizada no município de Jaguaré, ES, com a utilização de cafeeiros (Café 'Conilon' - Coffea canephora Pierre), com cinco anos de idade, implantados no espaçamento de 3,30 x 1,20 m, irrigados por aspersão fixa permanente. Foram avaliados seis tratamentos, cada um contendo um total de 70 plantas. O tratamento T1 era não irrigado; o tratamento T2 tinha irrigação sem interrupção e os tratamentos T3, T4, T5 e T6 eram irrigados com interrupção da irrigação por três, cinco, sete e nove semanas, respectivamente, a partir do dia 5 de julho de 2010. O estudo mostrou que os tratamentos T1, T2 e T6 apresentaram maiores percentuais de uniformidade da florada. O estádio E5 de desenvolvimento do botão floral se mostrou como melhor estádio para se definir a hora certa de retornar a irrigação. Os resultados das avaliações mostraram que não houve diferença significativa para o crescimento dos ramos plagiotrópicos em função dos tratamentos aplicados.
\end{abstract}

Palavras-Chave: irrigação, manejo de irrigação, café, floração.

\footnotetext{
${ }^{1}$ Engenheiro Agrônomo, Pós Graduado em Gestão Comercial, Empresário da BRAF, Centrais de Abastecimento do Espírito Santo, Rodovia BR 101 Norte, Km. 67, Bairro Nova Era, 29940-106, São Mateus, ES.E-mail: maricleimarsetti@ hotmail.com

2 Engenheiro Agrônomo, Doutor em Engenharia Agrícola/Irrigação e Drenagem, Professor da Universidade Federal do Espírito Santo, Centro Universitário Norte do Espírito Santo, Departamento de Ciências Agrárias e Biológicas, Rodovia BR 101 Norte, Km. 60, Bairro Litorâneo, 29932-540, São Mateus, ES. E-mail: robsonbonomo@ceunes.ufes.br

${ }^{3}$ Engenheiro Agrônomo, Doutor em Produção Vegetal, Professor da Universidade Federal do Espírito Santo, Centro Universitário Norte do Espírito Santo, Departamento de Ciências Agrárias e Biológicas, Rodovia BR 101 Norte, Km. 60, Bairro Litorâneo, 29932-540, São Mateus, ES. E-mail: partelli@yahoo.com.br

${ }^{4}$ Engenheira Agrônoma, Bolsista da FAPES, Acadêmica do Programa de Pós-Graduação em Agricultura Tropical, Universidade Federal do Espírito Santo, Centro Universitário Norte do Espírito Santo, Rodovia BR 101 Norte, Km. 60, Bairro Litorâneo, 29932-540, São Mateus, ES. E-mail: gizellesab@ hotmail.com
} 


\title{
WATER DEFICIT AND CLIMATIC FACTORS ON THE FLOWERING UNIFORMITY OF IRRIGATED CONILON COFFEE
}

\begin{abstract}
The coffee crop is an activity of high importance in the north of the Espírito Santo. The use of irrigation in the cultivation of coffee Conilon capixaba has provided greater productivity, good uniformity of flowering, and better quality of final product . This study was conducted in an area located in the municipality of Jaguaré, ES, with the use of coffee (Café 'Conilon' - Coffea canephora Pierre), of five years of age, planted in spacing of $3.30 \times 1.20 \mathrm{~m}$, under fixed sprinkler irrigation. Six treatments were evaluated, each containing a total of 70 plants. The treatment T1 was not irrigated; treatment T2 was irrigated without interruption and T3, T4, T5 and T6 were irrigated with interruption of irrigation for three, five, seven and nine weeks, respectively, from the July 5, 2010. The study showed that the treatments T1, T2 and T6 showed higher percentages of uniform flowering. The E5 floral bud development stage proved as the best stage to define the right time to return to irrigation. The results of evaluations showed no significant difference in the growth of plagiotropic branches in the treatments studied.
\end{abstract}

Keywords: irrigation, irrigation management, coffee, flowering.

\section{INTRODUÇÃO}

A cafeicultura brasileira passou por grandes transformações nos últimos 20 anos, e já não é raro produzir mais de $6000 \mathrm{~kg}$ por hectare. A mudança significativa foi na densidade de plantas, com o acréscimo de três mil cafeeiros por hectare, e outra, mais recente, foi o aumento da área irrigada de 10 mil para 250 mil hectares (SANTINATO; FERNANDES, 2012).

O Estado do Espírito Santo é considerado o segundo maior produtor nacional de café, responsável por $25,9 \%$ da produção nacional, com 11,573 milhões de sacas de 60 quilos beneficiadas na safra de 2011/2012, destacando-se o plantio das espécies Arábica e Conilon, sendo este último, responsável pela participação de $60,95 \%$ na produção do país, colocando o estado como maior produtor da espécie robusta, com uma produção de 8,494 milhões de sacas de 60 quilos na safra de 2011/2012 (CONAB, 2012).

Na produção do Conilon, destacam-se os municípios de Vila Valério, Jaguaré, Sooretama, Linhares, Rio Bananal, São Mateus, Nova Venécia, Pinheiros e São Gabriel da Palha, a produção de cada município é superior a 400 mil sacas por ano (INCAPER, 2011).

A utilização mais acentuada de tecnologias, associadas à irrigação, tem aumentado gradativamente a produtividade do café Conilon no estado do Espírito Santo. Esse aumento, portanto, deve-se basicamente à renovação de lavouras com variedades com maior potencial produtivo, aos bons tratos culturais, e um manejo de irrigação adequado. Sendo que, para se alcançar sucesso com a agricultura irrigada, é imprescindível a escolha do sistema de irrigação mais adequado à determinada situação (PARTELLI et al., 2013) 
O café é uma espécie de floração gregária, ou seja, todas as plantas de uma região florescem simultaneamente, com número de floradas variável, ao longo do ano nas regiões equatoriais. Assim, enquanto na Região Sudeste do Brasil ocorrem de duas a três florações com intensidades decrescentes, na Costa Rica verificam-se até 15 (ALVIM, 1973 apud SOARES et al., 2005). Esse hábito reprodutivo provoca dificuldades relacionadas às colheitas parciais, controle de doenças, e pragas e redução na qualidade dos grãos (RENA; MAESTRI, 1986 apud SOARES et al., 2005).

Um fator importante e polêmico relacionado à irrigação do cafeeiro é a necessidade da suspensão de irrigações para floração, estresse hídrico ou simplesmente déficit hídrico para a quebra de dormência do botão floral para indução da floração, proporcionando uma uniformização ou sincronização da florada, sem causar danos à produção. Entretanto, ainda não se tem conhecimento fisiológico suficiente para aplicar o déficit hídrico ideal, e na época correta para atingir esses objetivos sob condições de campo, em função notadamente das diferenças climáticas (temperatura e umidade relativa do ar) de cada região cafeeira e de cada ano, em cada região, bem como das condições da lavoura, quanto a sua idade, espaçamento, espécie e variedade (SANTINATO et al., 2008).

O estabelecimento de estresse hídrico na planta pela suspensão das irrigações estimula o crescimento após o reinício das irrigações. Guerra et al. (2005), observaram em 2005, depois de quatro ciclos anuais de suspensão das irrigações, que as plantas dos regimes hídricos sujeitos a estresse hídrico controlado apresentaram maior altura, número de ramos plagiotrópicos e número de nós nos ramos, quando comparadas às plantas do tratamento irrigado durante todo ano. A maior produtividade também foi observada nos tratamentos com estresse moderado e adequado, isso se deve ao melhor enchimento dos grãos devido à uniformidade de maturação quanto ao maior desenvolvimento vegetativo das plantas.

Barros et al. (1978 apud SOARES et al., 2005) sugeriram que as condições que podem promover a abertura floral no cafeeiro são: a queda rápida de temperatura, independentemente da ocorrência de déficit hídrico, chuvas abundantes ou irrigações após um longo período de seca e as quedas bruscas de temperatura, seguidas por suprimento de água, tanto sob a forma de chuvas quanto de irrigação, complementar ou sinergicamente. Sendo que no Sudeste do Brasil, Barros et al. (1973 apud SOARES et al., 2005) constataram que a iniciação floral ocorre à medida que os dias se encurtam, a temperatura se reduz e a estação da seca avança.

De maneira geral, recomenda-se o uso imitando-se a natureza, sendo em regiões frias de 45 a 60 dias, em regiões médias de 30 a 45 dias e quentes até no máximo de 30 dias antes da floração que irá variar de ano para ano (SANTINATO et al., 2008).

Considerando o exposto, o trabalho teve como objetivo avaliar os efeitos do déficit hídrico, na dormência dos botões florais e na abertura floral do café 'Conilon' (Coffea canephora Pierre) produzido sob condições climáticas do norte do estado do Espírito Santo. 


\section{MATERIAL E MÉTODOS}

O trabalho foi desenvolvido no município de Jaguaré, com latitude $18^{\circ} 54^{\prime}$ 18,49" Sul, longitude 4005'19,20" Oeste e altitude média de $60 \mathrm{~m}$. O município está localizado na região norte do Espírito Santo. O clima é do tipo subúmido, com baixa deficiência hídrica, megatérmico, com evapotranspiração no verão de $48 \%$ (NÓBREGA et al., 2008), com terras quentes, planas e de transição entre chuvosa/seca (FEITOZA et al., 2001). O experimento foi conduzido no período de junho a setembro de 2010, numa área experimental de três hectares, de topografia plana, típica da região de Jaguaré.

O experimento foi instalado em uma área com café Conilon, cultivar 02 , com cinco anos de idade, implantados no espaçamento de 3,30 m entre linhas e 1,20 m entre plantas. As plantas se encontravam em bom estado nutricional quando o experimento foi implantado.

O sistema de irrigação foi do tipo aspersão fixa permanente, composto por aspersores, modelo Júnior com diâmetro de 1/2", da marca Asperjato, com dois bocais $(2,8 \times 2,5 \mathrm{~mm}$ Laranja), espaçados $15 \times 15 \mathrm{~m}$, com vazão de $816 \mathrm{~L} \mathrm{~h}^{-1}$, a uma pressão de $25 \mathrm{kPa}$.

A área experimental foi instalada em um Argissolo apresentando na camada de $0-20$ $\mathrm{cm} 70 \%$ de areia, $8 \%$ de silte e $22 \%$ de argila, classe textural Franco Argilo - Arenoso, com 11,5 e $9,2 \%$ (em peso) de valores médios de capacidade de campo e ponto de murcha permanente, sendo estes valores determinados em laboratório através do aparelho extrator de Richards. A densidade aparente média é igual a $1,78 \mathrm{~g} \cdot \mathrm{cm}^{-3}$. A análise química indicou boa disponibilidade de nutrientes no solo e serviu de base para todo o programa de adubação da cultura.

Os dados meteorológicos utilizados para o estudo dos efeitos das variáveis climáticas sobre o desenvolvimento do botão floral foram obtidos de uma estação meteorológica automática de superfície, instalada no local do experimento, na qual foram registrados dados horários de temperatura máxima, mínima e média do ar, umidade relativa do ar, velocidade do vento, radiação solar e precipitação.

Foram implantados seis tratamentos experimentais, cada um contendo um total de 70 plantas, das quais foram demarcadas dez, ao acaso, para avaliação, sendo considerado cada planta como uma repetição. Os tratamentos estudados foram:

- Tratamento T1: não irrigado;

- Tratamento T2: irrigado sem interrupção, com irrigações efetuadas quando a tensão de água no solo atingia o valor limite de 30 a 40 $\mathrm{kPa}$;

- Tratamento T3: irrigado com interrupção da irrigação por três semanas a partir do dia 5 de julho de 2010;

- Tratamento T4: irrigado com interrupção da irrigação por cinco semanas a partir do dia 5 de julho de 2010;

- Tratamento T5: irrigado com interrupção da irrigação por sete semanas a partir do dia 5 de julho de 2010; e 
- Tratamento T6: irrigado com interrupção da irrigação por nove semanas a partir do dia 5 de julho de 2010.

A irrigação para o tratamento irrigado sem interrupção foi controlada por uma bateria de tensiômetros. A bateria foi dividida em três setores compostos por dois tensiômetros, com vacuômetro, do tipo metálico (Bourdon), instalados nas profundidades de 20 e $40 \mathrm{~cm}$. A irrigação era estabelecida quando os tensiômetros instalados na profundidade de $20 \mathrm{~cm}$, marcavam uma tensão média em torno de 30 a $40 \mathrm{kPa}, \mathrm{e}$ os tensiômetros instalados na profundidade de $40 \mathrm{~cm}$ marcavam uma tensão próximo de $10 \mathrm{kPa}$. O tempo de irrigação foi de 7 horas, para a aplicação de uma lâmina de $25 \mathrm{~mm}$. Esse procedimento foi utilizado para irrigar o tratamento T2, no qual a irrigação era sem interrupção, e também aplicada nas demais áreas, logo após o fim dos respectivos períodos com interrupção das irrigações.

A avaliação das floradas foi feita conforme a metodologia proposta por Womer e Guituanja (1970), citados por Camayo e Arcila (1996), (Figura 1), definindo o estádio E5 como indicador da contagem do número de flores em cada florada. Sendo que, das dez plantas demarcadas previamente, foram selecionados, aleatoriamente, dois ramos plagiotrópicos (um no sentido norte e outro sul) do terço médio superior de cada planta, ramos nos quais foram feitas as contagens dos números de flores e total de nós.
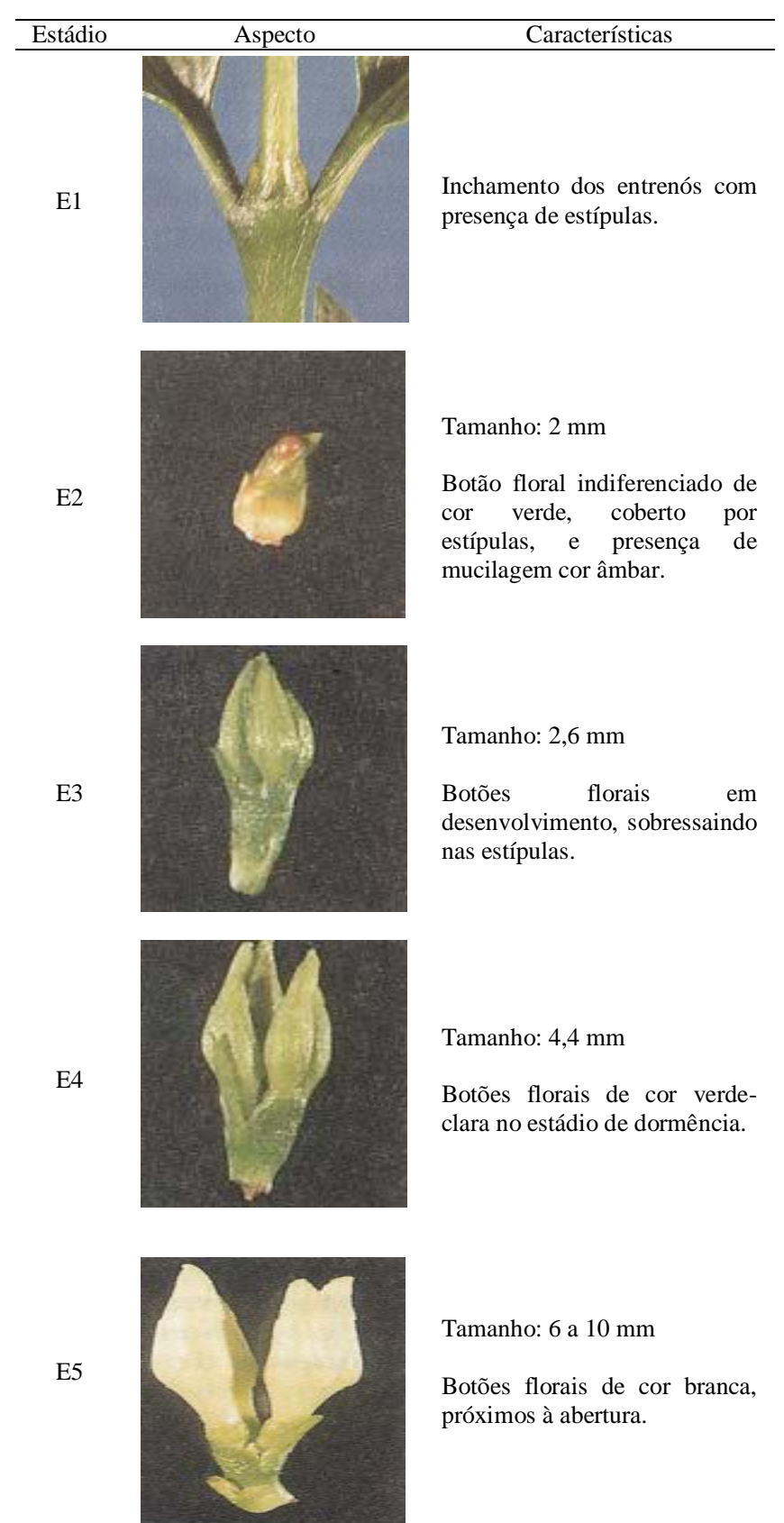

Tamanho: 6 a $10 \mathrm{~mm}$

Botões florais de cor branca, próximos à abertura.

E6

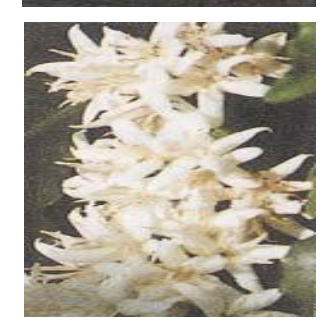

Flores. 
Os dados foram submetidos à análise de variância. As médias foram comparadas utilizando-se o teste de Tukey a 0,05 de probabilidade. Para o comportamento dos elementos climáticos e emissão dos botões florais e flores, utilizou-se a análise descritiva, conforme descritas por Soares (2001).

\section{RESULTADO E DISCUSSÃO}

A imposição dos déficits hídricos pela supressão da irrigação foi feita entre 05 de julho a 30 de setembro de 2010, (Figura 2), de acordo com cada tratamento. Na mesma figura observa-se que durante este período ocorreram vários eventos de chuva, porém de baixa precipitação total, $92 \mathrm{~mm}$ no período, não apresentando efeito sobre a quebra da dormência dos botões florais, além disso, estes não tinham ainda atingido o estádio E4 de desenvolvimento (Figura 1), momento adequado para que ocorra a quebra da dormência. A temperatura média do ar (Figura 2) variou de forma habitual durante o período, o que também não foi suficiente para interferir na dormência dos botões florais.

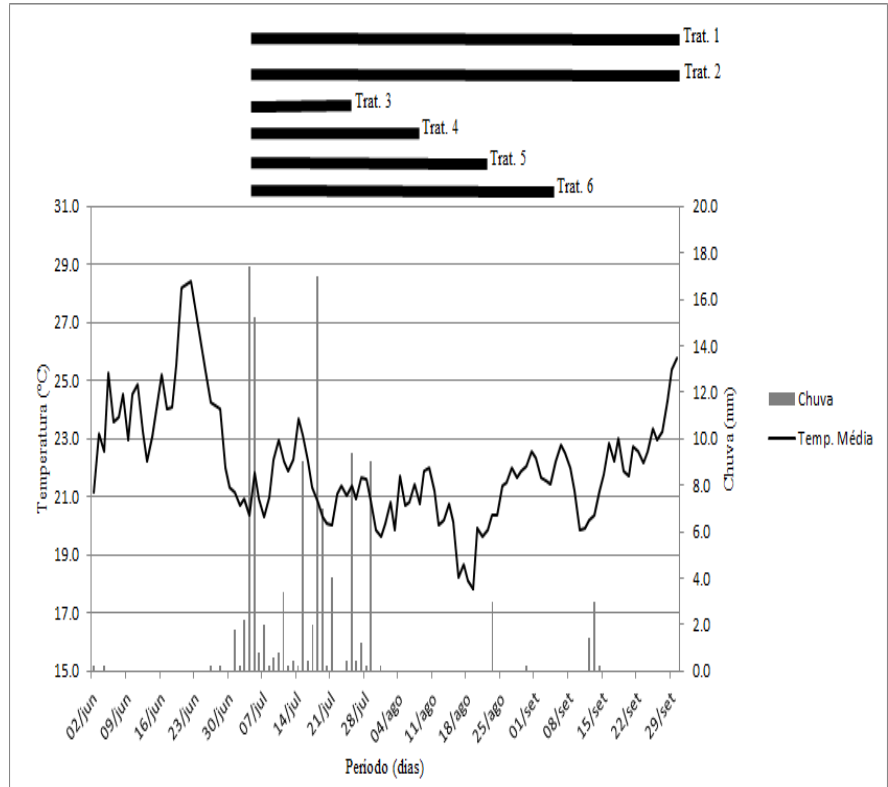

Figura 2. Valores de distribuição das chuvas, temperatura média e duração de cada tratamento durante a condução do experimento.
A contagem inicial dos botões florais foi feita no mesmo dia (05 de julho/2010) para todos os tratamentos, sendo observada uma distribuição regular em relação aos estádios de desenvolvimento, na qual os mesmos estavam concentrados em torno de $80 \%$ no estádio E2, exceto o tratamento $\mathrm{T} 5$, que teve uma distribuição de $36 \%$ no estádio E2, $20 \%$ no estádio E3 e 35,5\% no estádio E5, conforme observado na Figura 3. Foi estabelecido que a contagem final fosse feita num período máximo de uma semana após o encerramento de cada tratamento, em que se pode observar que os tratamentos T1, T2 e T6 tiveram uma concentração de flores emitidas no estádio E6 de desenvolvimento (Figura 3) de 97\%, 94\% e $95,7 \%$, respectivamente. Para os tratamentos T3, T4 e T5 não foram observados uma uniformidade de emergência dos botões florais acima de $60 \%$ para nenhum de desenvolvimento do botão floral.

O reinício da irrigação para os tratamentos T3 e T4 não resultou em floração, uma vez que os botões florais destes tratamentos encontravam-se entre os estádios E2 e E3, ainda não sensíveis ao déficit hídrico, conforme afirmado por Crisosto et al. (1992). Para o tratamento T5 foi verificado uma pequena influência em torno de 50\%, (Figura 3).

A avaliação final dos estádios de desenvolvimento dos botões florais mostrou grande desuniformidade para os tratamentos T3, T4 e T5 (Figura 3), tendo sido encontrados nestes, botões de todos os estádios de desenvolvimento.

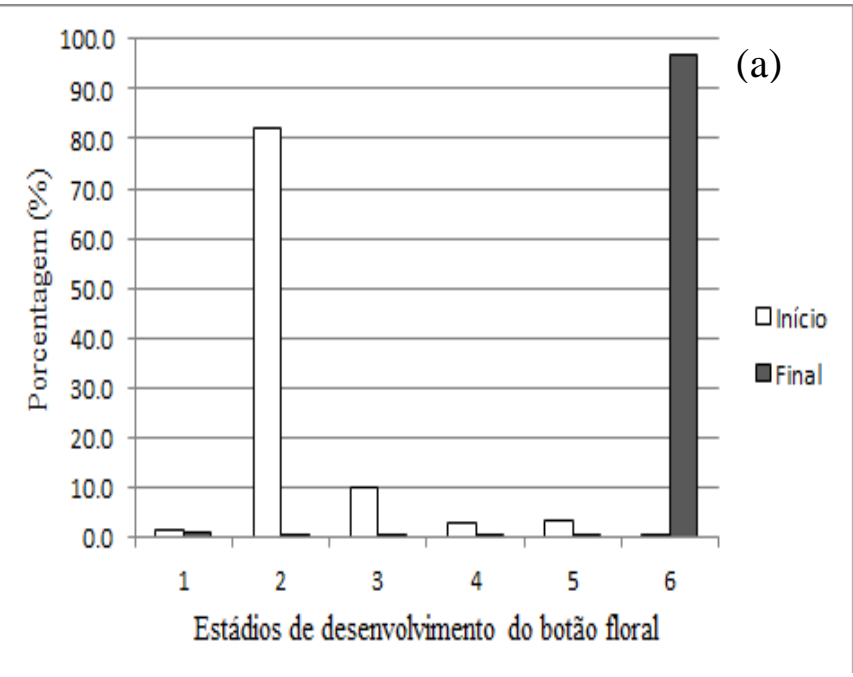




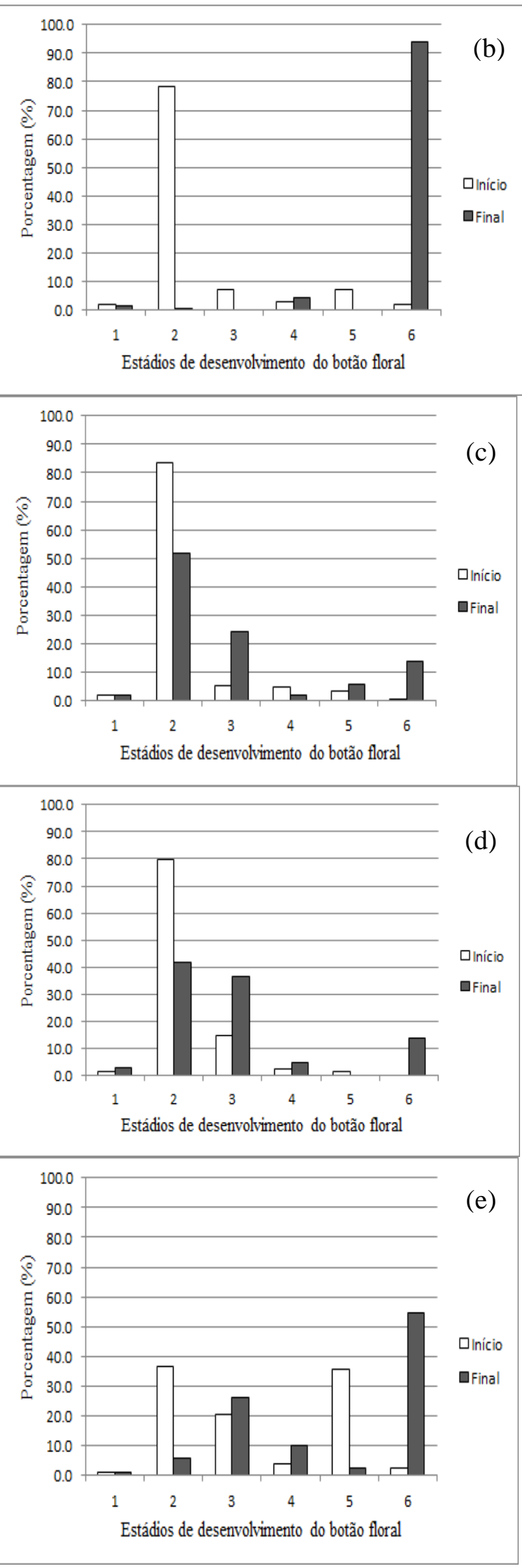

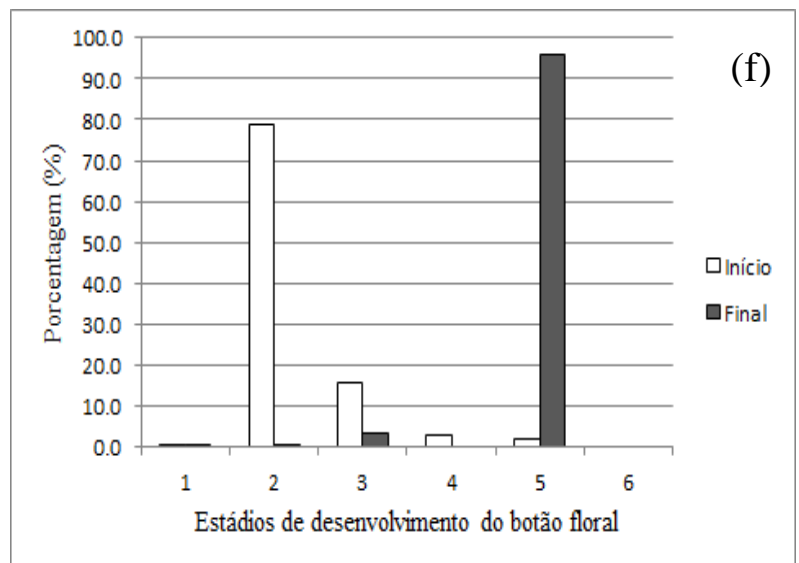

Figura 3. Porcentagem de distribuição dos botões florais nos estádios E1, E2, E3, E4 e E5 e flores (estádio E6) emitidas no início (05 de julho) e no final do experimento, de acordo com os estádios de desenvolvimento do botão floral para o cafeeiro Conilon nos tratamentos T1 (a), T2 (b), T3 (c), T4 (d), T5 (e) e T6 (f).

Provavelmente, os déficits hídricos foram aplicados em épocas inadequadas, quando a maioria dos botões florais ainda não estavam susceptíveis, estádio E4, à quebra de dormência, tanto pela irrigação ou precipitação. Segundo Soares (2001), para ocorrer uma melhor adequação do déficit hídrico com o desenvolvimento dos botões florais, o restabelecimento das irrigações deve ocorrer quando a maior parte dos botões florais se encontre no estádio E4, possibilitando uma maior uniformidade entre as floradas.

$\mathrm{Na}$ Tabela 1, são apresentados os somatórios dos números de botões florais emitidos até o estádio de desenvolvimento E5 e as flores emitidas, estádio E6, com a análise estatística para os devidos tratamentos. Os tratamentos T3, T4 e T5 tiveram os melhores resultados estatisticamente quando relacionado ao número de botões florais emitidos, sendo que o tratamento $\mathrm{T} 1$ teve a menor emissão de botões, porém não diferindo estatisticamente dos tratamentos T2 e T6. 
O tratamento T1 teve a maior emissão de flores, porém não diferiu estatisticamente dos tratamentos T6 e T2, este último também não apresentou diferença significativa em relação ao tratamento T5.

Tabela 1. Número de botões florais emitidos até o estádio de desenvolvimento E5 e o número de flores emitidas por tratamento.

\begin{tabular}{|c|c|c|c|c|}
\hline \multirow{2}{*}{$\begin{array}{c}\text { TRATAMENTOS } \\
1\end{array}$} & \multicolumn{2}{|c|}{$\begin{array}{c}\mathrm{N}^{\circ} \text { DE BOTÕES } \\
\text { FLORAIS EMITIDOS }\end{array}$} & \multicolumn{2}{|c|}{$\begin{array}{c}\mathrm{N}^{\circ} \mathrm{DE} \\
\text { FLORES } \\
\text { EMITIDAS }\end{array}$} \\
\hline & 142 & B & 4548 & A \\
\hline 2 & 199 & B & 3116 & $\mathrm{AB}$ \\
\hline 3 & 1261 & A & 200 & $\mathrm{C}$ \\
\hline 4 & 1168 & A & 191 & $\mathrm{C}$ \\
\hline 5 & 1111 & A & 1348 & $\mathrm{BC}$ \\
\hline & 201 & B & 4464 & A \\
\hline
\end{tabular}

*Os valores seguidos pela mesma letra maiúscula na coluna não diferem entre si pelo teste de Tukey, a 0,05 de probabilidade.

Os ramos plagiotrópicos das plantas avaliadas de todos os tratamentos tinham comprimentos similares no início, indicando uma boa uniformidade das plantas para execução do trabalho. A mesma uniformidade foi verificada na contagem final do número de nós de cada tratamento (Figura 4), ou seja, nenhum tratamento interferiu significativamente no crescimento dos ramos.

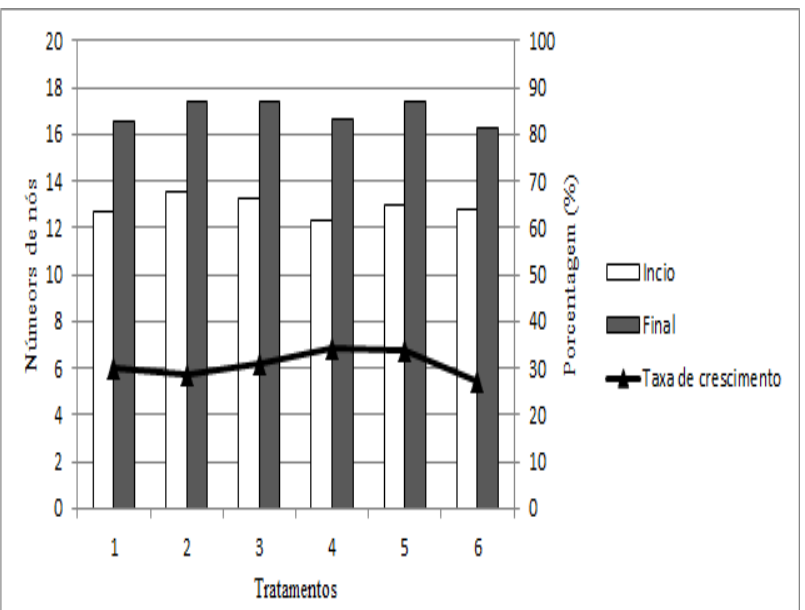

Figura 4. Números médios de nós no início e no final do experimento e a taxa de crescimento em porcentagem.
Na Tabela 2 estão descritos os números de nós no início e final do experimento dos tratamentos avaliados, bem como uma análise estatística e a taxa de crescimento em porcentagem dos ramos. Observou-se que não houve diferença estatística na contagem inicial e final dos tratamentos, mostrando por outro lado que todos os ramos independentes dos tratamentos aplicados cresceram na mesma proporção, ou seja, as taxas de crescimento foram bem próximas uma das outras.

Ao comparar o crescimento dos ramos antes e depois da aplicação dos tratamentos, verifica-se que os tratamentos T3, T4 e T5 promoveram os maiores crescimentos. Esse comportamento corrobora com Matiello (2006), ao constatar que o estresse hídrico pode estimular o número de gemas florais no cafeeiro. Em relação aos outros tratamentos, T1, T2 e T6, os crescimentos dos ramos não foram significativos.

Tabela 2. Números médios de nós no início e no final do experimento e a taxa de crescimento em porcentagem.

\begin{tabular}{ccccccc} 
& \multicolumn{7}{c}{ TRATAMENTOS } \\
\cline { 2 - 6 } & 1 & 2 & 3 & 4 & 5 & 6 \\
\cline { 2 - 6 } Início & $12,7 \mathrm{Aa}$ & $13,6 \mathrm{Aa}$ & $13,3 \mathrm{Ab}$ & $12,4 \mathrm{Ab}$ & $13,0 \mathrm{Ab}$ & $12,8 \mathrm{Aa}$ \\
& & & & & & \\
Final & $16,5 \mathrm{Aa}$ & $17,4 \mathrm{Aa}$ & $17,4 \mathrm{Aa}$ & $16,6 \mathrm{Aa}$ & $17,4 \mathrm{Aa}$ & $16,3 \mathrm{Aa}$ \\
$\begin{array}{c}\text { Tx. de } \\
\text { crescimento } \\
\text { (\%) }\end{array}$ & 29,92 & 28,41 & 30,94 & 34,41 & 33,98 & 27,34 \\
& & & & & & \\
\hline
\end{tabular}

*Os valores seguidos pela mesma letra maiúscula nas linhas e pela mesma letra minúscula nas colunas não diferem entre si pelo teste de Tukey, a 0,01 de probabilidade.

Um acompanhamento do desenvolvimento do botão floral em estádios, associado à aplicação do déficit hídrico no momento certo, 


\section{DÉFICIT HÍDRICO E FATORES CLIMÁTICOS NA UNIFORMIDADE DA FLORADA DO CAFEEIRO CONILON IRRIGADO}

poderá afetar de maneira significativa o pegamento floral, melhorando, assim, a qualidade do produto final.

Não obstante as vantagens já descritas em relação a uniformidade da florada deve-se ressaltar a importante economia de água possibilitada por essa técnica, coincidindo ainda com o período crítico (julho a setembro) de disponibilidade de água nos cursos d'água e reservatórios da região. Soma-se a isso à economia de energia e mão-de-obra gerada no período em que o sistema de irrigação não é acionado.

\section{CONCLUSÕES}

Os tratamentos T1, T2 e T6, apresentaram as maiores porcentagens de uniformidade da florada (estádio E6);

O estádio de desenvolvimento do botão floral E5 é o principal estádio para se definir o momento correto de retornar a irrigação;

O emprego de um período de supressão das irrigações não afetou o crescimento dos ramos plagiotrópicos das plantas avaliadas, independente do tratamento aplicado.

\section{REFERÊNCIAS BIBLIOGRÁFICAS}

CAMAYO, V. G. C.; ARCILA, P. J. Estudio anatómico e morfológico de la diferenciacion e desarrolo de las flores del cafeto Coffea arábica L. variedad Colombia. Cenicafé, v. 47, n. 3, p.121-139, 1996.

CONAB - Companhia Nacional de Abastecimento. Café: Conjuntura no ES. Vitória, 2012. 13p.

CRISOSTO, C. H.; GRANTZ, D. A.;
MEINZER, F. C. Effects of water deficit on flower opening in coffee (Coffea arabica L.). Tree Physiology, v. 10, n. 2, p. 127-139, 1992.

FEITOZA, L. R.; STOCKING, M.; RESENDE, $M$. Natural resources information systems for rural development: Approaches for Espirito Santo State, Brazil. Vitória: Incaper, 2001. 223p.

GUERRA, A. F.; ROCHA, O. C.; RODRIGUES, G. C.; SANZONOWICZ, C.; SAMPAIO, J. B. R.; SILVA, H. C.; ARAÚJO, M. C. Irrigação do cafeeiro no Cerrado: Estratégia de manejo de água para uniformização de florada. Planaltina, DF: Embrapa Cerrados, 2005. 4p. (Embrapa Cerrados. Comunicado Técnico, 122).

INCAPER - Instituto Capixaba de Pesquisa, Assistência Técnica e Extensão Rural. Espírito Santo bate recorde histórico na safra de café, 2011. Disponível em: $<$ http://www.incaper.es.gov.br/noticia_comple ta.php?id=372> . Acesso em: 17 jul. 2013.

MATIELLO, J. B. Estresso ou não meu cafezal? Revista Brasileira de Tecnologia Cafeeira: Coffea, Ano 3, n. 10, p. 35-36, 2006.

NÓBREGA, N. E. F. da.; SILVA, J. G. F. da; RAMOS, H. E. dos A.; PAGUNG, F. dos S. Balanço hídrico climatológico e classificação climática de Thornthwaite e Köppen para o município de Linhares - ES. In: XVIII CONGRESSO NACIONAL DE IRRIGAÇÃO E DRENAGEM. São Mateus - ES, 2008.

PARTELLI, F. L.; OLIVEIRA, M. G.; SILVA, M. B. da. Café Conilon: Qualidade, adubação e irrigação. In: BONOMO, R.; REIS, E. F. Irrigação do Conilon: Manejo de irrigação. 1. ed. São Mateus, ES: Autores, 2013. cap. 4, p. 53-72.

SANTINATO, R.; FERNANDES, A. L. T.; 
FERNANDES, D. R. Irrigação na cultura do café. 2. ed. Belo Horizonte: Editora O Lutador, 2008. 476p.

SANTINATO, R.; FERNANDES, A. L. T. Cultivo de cafeeiro irrigado por gotejamento. 2. ed. Uberaba: Editora O Lutador, 2012. 388 p.

SOARES, A. R. Irrigação, fertirrigação, fisiologia e produção em cafeeiros adultos na região da zona da mata de Minas Gerais. 2001. 84 f. Dissertação (Mestrado em Engenharia Agrícola) - Universidade Federal de Viçosa, Viçosa.

SOARES, A. R.; MANTOVANI, E. C.; RENA, A. B.; SOARES, A. A. Irrigação e fisiologia da floração em cafeeiros adultos na região da zona da mata de Minas Gerais. Acta Scientiarum Agronomy, v.27, n.1, p.117-125, 2005. 